\title{
Anthropometric dimensions on nutritional grade among school children
}

\begin{abstract}
Background and objectives: The child under nutrition is highly prevalent in low income and middle-income countries resulting in substantial increases in mortality and overall disease burden. Therefore, the present study was designed to evaluate anthropometric dimensions on nutritional grade among school children at urban area of Dhanusha District, Nepal.
\end{abstract}

Materials and methods: A cross-sectional observational survey was done in 135 school children of aged 4-15years. A semi structured questionnaire was used to collect data through face to face interview. Height, weight were measured in the metric system using standardized technique and BMI was also calculated comparing with the WHO standard. Data were analyzed using SPSS 18 version and Microsoft Excels 2007. The p-value was considered statistically significant at $<0.05$.

Results: The prevalence of underweight, wasting and stunting was $7.40 \%, 52.59 \%$ and $28.88 \%$ respectively. The highest number of boys were in underweight than girls in 7-9years age and was statistically insignificant $(\mathrm{p}=0.451)$. Most of the boys were wasted than girls in 10-12years with $47.88 \%$ followed by $13-15$ years of $21.12 \%$ and was statistically insignificant $(\mathrm{p}=0.213)$. The highest number of respondents were stunting in $10-12$ years age of $48.71 \%$ followed by $13-15$ years age with $30.76 \%$ and was statistically insignificant $(\mathrm{p}=0.367)$.

Conclusion: The prevalence of underweight was low, wasting was high and stunting was moderate among school children when compared with WHO standard. Government should introduce awareness programs through community participation, involvement of NGOs and other sectors affording nutritious foods.

Keywords: under nutrition, anthropometric, children, urban, wasting, stunting
Volume 6 Issue 3 - 2017

\author{
Satyam Prakash,' Khushbu Yadav² \\ 'Department of Biochemistry, Janaki Medical College, Janakpur, \\ Nepal \\ ${ }^{2}$ Medical Microbiologist and Lecturer, Krishna Medical Technical \\ Research Center, Janakpur, Nepal
}

Correspondence: Satyam Prakash, Assistant Professor, Department of Biochemistry, Janaki Medical College Teaching Hospital,Tribhuvan University, Janakpur - 45600, Nepal, Tel +9779844405444 +9779841603704,

Email sprakashy2424@gmail.com

Received: January 28, 2017 | Published: March 31, 2017

\section{Introduction}

The combination of the food, fuel and financial crises coming together is threatening the livelihoods and food security of millions of people in developing countries which has enhanced the interest of researchers in under nutrition. Under nutrition continues to be an important cause of ill-health and premature mortality and morbidity among children. ${ }^{1}$ Nutritional deprivation is rampant in children of school age. Since deficient physical growth is naturally reflected in their suboptimal mental achievement, the assessment of nutritional status is essential for making development towards improving overall health of the school age children. ${ }^{2}$ Organization plays a chief role in conveying knowledge and prevention of nutritional deficiencies and several other diseases which provides an ideal setting for promoting good health behavior. The most significant period of a student's life is spent at school and colleges and it is here that their lifetime beliefs and habits develop. ${ }^{3,4}$ Schools are considered as perfect settings for health promotion among children and school staffs. ${ }^{5,6}$ School age is a dynamic period of physical growth as well as of mental development of the child. The nutritional status of school-aged children impacts their health, cognition and subsequently their educational achievement. Children in the age group of 5-14years are often considered as school-age. Since 1972, the United Nations Educational Scientific and Cultural Organization(UNESCO) consider 6-11years as primary school age and 12-17years as secondary school age for statistical purposes. ${ }^{7}$ The foundations of good health and sound mind are laid during the school age period. ${ }^{8}$ The children are classified using three categories: 'underweight'(low weight-for-age), 'stunting'(low height-for-age) or 'wasting'(low weight-for-height). Anthropometric examination is an almost mandatory tool in any research to assess health and nutritional condition in childhood. Based on the age, body weight and height, a number of indices such as height-for-age, weightfor-height and body mass index have been suggested. ${ }^{9}$ School children are not thought of as "at risk" population and little attention is paid to their nutritional assessment. ${ }^{10}$ Nepal has high rates of under nutrition contributing to a huge absolute number of undernourished children in the world. The problem is more severe in third world countries affecting children of all ages especially the under fives. According to Nepal Demographic Health and Survey (2011), the nutritional status of children under five as measured by weight-for- height was $11 \%$ of children wasted and $3 \%$ was severely wasted..$^{11}$ The use of different growth standards can give rise to difference in prevalence of under nutrition. Although urban areas have traditionally been considered better served in terms of healthcare, education and sanitation but significant challenges are faced by government in urban food security and nutrition programming in densely packed population where in and out migration is a constant feature. The present study was conducted in a school of urban area located in Janakpurdham, Dhanusha District, Nepal which is also considered as birth place of Goddess Sita. No reliable estimates of nutritional status are available from this 
mentioned area. Therefore, this study was designed to evaluate the nutritional status by anthropometric dimensions in school children of Dhanusha District, Nepal. The results of the present study may be useful for policy makers to formulate various nutritional development health care programs among the school children.

\section{Materials and methods}

\section{Study design}

A cross-sectional observational survey was done in a school children aged 4-15years of Dhanusha district in 2016. A total of 135 students from nursery to class 8 were selected by purposive sampling method. Before proceeding to this study, written letter of consent was obtained from the Sarvodaya English Boarding School, Janakpur and Krishna Medical Technical Research Center, Ramanand Chowk, Janakpur Nepal. After obtaining authorized consent from the management, the school was visited and objective of the study was explained to the students. The data was collected using standard questionnaire. The children with age greater than 4years were included whereas children above $15 y e a r s$ and those who did not filled questionnaire appropriately were excluded.

\section{Data collection and processing}

Students in a class were given a brief description about the importance of anthropometric examination and the impact of poor diet upon health. A semi structured questionnaire was used to collect data through face to face interview. Each child's height and weight were measured in the metric system using standardized technique. BMI was calculated by using following standard equation.

\section{BMI = weight $(\mathrm{kg}) /$ height $\left(\mathrm{m}^{2}\right)$}

The cut-offs for classification of nutritional status was compared with the WHO standard range (Table 1$)^{12}$ and interpreted as measured the weight for age(underweight), height for age(stunting) and BMI for age(thinness). Data were edited, processed and analyzed with the use of the SPSS 18 version and Microsoft Excels 2007. The p-value $<0.05$ was considered as statistically significant.

Table I Age wise comparison of weight, height and BMI with WHO standard

\begin{tabular}{|c|c|c|c|c|c|c|}
\hline \multirow{2}{*}{ Age group(yrs) } & \multicolumn{2}{|c|}{$\begin{array}{l}\text { WHO standard range(kg) for weight } \\
\text { for age }\end{array}$} & \multicolumn{2}{|c|}{$\begin{array}{l}\text { WHO standard range(kg) for height } \\
\text { for age }\end{array}$} & \multicolumn{2}{|c|}{$\begin{array}{l}\text { WHO standard range(kg) for BMI } \\
\text { for age }\end{array}$} \\
\hline & Boys & Girls & Boys & Girls & Boys & Girls \\
\hline 4 & $12.2-19$ & $|2.5-2|$ & $95.4-110$ & $92.7-116$ & $|4|-.\mid 7.8$ & $13.7-18$ \\
\hline 5 & |4.6-26.4 & $14.2-27$ & $99.6-126.8$ & $98.5-126.5$ & $\mid 3.1-18.3$ & $12.8-18.9$ \\
\hline 6 & |6.|-29.8 & I5.5-30.4 & $104.5-133.5$ & $103.2-133$ & |3.2-18.7 & $12.8-19.4$ \\
\hline 7 & 17.9-33.7 & $17-36.4$ & $109.4-139.9$ & $108.1-139.5$ & $13.3-19.3$ & $12.9-20$ \\
\hline 8 & 19.8-38.2 & 18.9-39.5 & $1 \mid 4.1-146$ & || $3.1-146 . \mid$ & $13.4-20$ & $|3-2|$ \\
\hline 9 & $21.6-43.5$ & $21.1-45.2$ & $1 \mid 8.6-152.1$ & $118.3-152.9$ & $13.6-20.9$ & $13.3-20$ \\
\hline 10 & $23.6-45$ & $23.7-47$ & $123-158.2$ & $123.8-159.9$ & $13.9-21.9$ & I3.6-23.| \\
\hline II & $25-55$ & $25-50$ & $127.5-165$ & $129.5-166.6$ & $14.2-23$ & |4-24.3 \\
\hline 12 & $30-65$ & $30-60$ & $132.6-172.7$ & |35.3-172.| & $|4.6-24|$. & $14.6-25.94$ \\
\hline 13 & $30-70$ & $35-65$ & |38.8-180.5 & $140.2-175.7$ & | $5 . \mid-25.2$ & $15.2-26.6$ \\
\hline 14 & $35-80$ & $40-70$ & $145.8-\mid 86.7$ & |43.6-| 77.7 & $15.6-26.3$ & 15.6-27.4 \\
\hline 15 & $40-80$ & $40-75$ & $150.8-190.7$ & | $45.7-\mid 78.3$ & $16.2-27$ & $16.1-28.2$ \\
\hline
\end{tabular}




\section{Results}

\section{Age and gender wise distribution of study population}

A total of 135 students were enrolled in this study and examined for weight for age, height for age and Body mass index for age where $82(60.74 \%)$ were boys and 53(39.25\%) were girls. The results are shown in Table 2 .

Table 2 Frequency distribution of total respondents

\begin{tabular}{llll}
\hline \multirow{2}{*}{ Age group(yrs) } & \multicolumn{2}{l}{ Gender } & \\
\cline { 2 - 4 } & Boys(\%) & Girls(\%) & \\
\hline 6-Apr & $8(9.75)$ & $5(9.4)$ & $13(9.62)$ \\
9-Jul & $22(26.82)$ & $9(16.98)$ & $31(22.96)$ \\
12-Oct & $34(41.46)$ & $26(49.05)$ & $60(44.44)$ \\
13-15 & $18(21.95)$ & $13(24.52)$ & $31(22.96)$ \\
Total & $82(60.74)$ & $53(39.25)$ & 135 \\
\hline
\end{tabular}

Prevalence of underweight, wasting and stunting among students

Out of 135 students, $10(7.40 \%)$ students were underweight, $71(52.59 \%)$ students were wasted and 39(28.88\%) students were stunted. The results are shown in Figure 1.

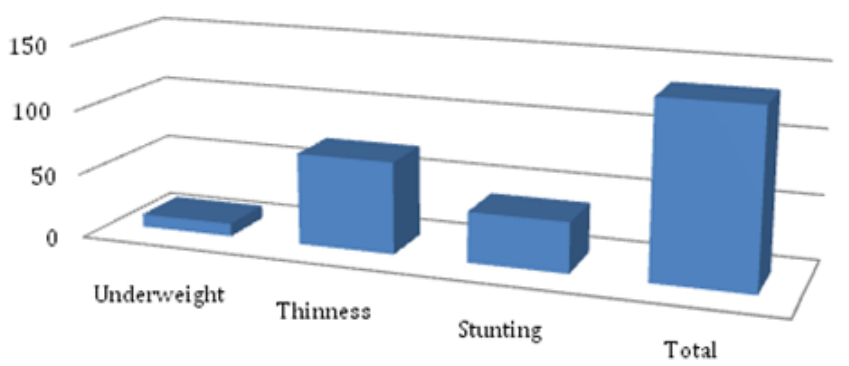

Figure I Prevalence of underweight, stunting, and wasting of study population.

Prevalence of underweight in respondents in relation to age group

Altogether 10 respondents were underweight, among them $7(70 \%)$ were boys and $3(30 \%)$ were girls. The highest numbers of boys were underweight in $7-9$ years age of $71.42 \%$. The association of underweight in relation to gender and age group was found to be statistically insignificant $(\mathrm{p}=0.451)$. The results are shown in Table 3 .

\section{Prevalence of wasting in respondents with relation to age group}

Altogether 71 respondents were considered wasted, among them 45(63.38\%) were boys and 26(36.61\%) were girls. Most of the boys were thinner than girls in 10-12years with 34(47.88\%) followed by $13-15 y$ years of $15(21.12 \%)$. In 4-6 and 7-9years age, the prevalence of wasting among students was similar. The association of thinness in relation to gender and age group was found statistically insignificant $(\mathrm{p}=0.213)$. The results are shown in Table 4.
Table 3 Association of underweight in relation to gender and age group

\begin{tabular}{|c|c|c|c|c|}
\hline \multirow{3}{*}{ Age group(yrs) } & \multicolumn{2}{|l|}{ Gender } & \multirow{3}{*}{-Total(\%) } & \multirow{3}{*}{ p-value } \\
\hline & & & & \\
\hline & Boys(\%) & Girls(\%) & & \\
\hline $4-6$ & $\mathrm{I}(\mathrm{I} 4.28)$ & $\mathrm{I}(33.33)$ & $2(20)$ & \\
\hline $7-9$ & $5(71.42)$ & 0 & $5(50)$ & \\
\hline $10-12$ & I(I4.28) & I(33.33) & $2(20)$ & 0.451 \\
\hline $13-15$ & 0 & I(33.33) & $\mathrm{I}(\mathrm{I0})$ & \\
\hline Total & $7(70)$ & $3(30)$ & 10 & \\
\hline
\end{tabular}

Table 4 Association of thinness in relation to gender and age group

\begin{tabular}{|c|c|c|c|c|}
\hline \multicolumn{3}{|c|}{ Gender } & \multirow{3}{*}{-Total(\%) } & \multirow{3}{*}{ p-value } \\
\hline \multicolumn{3}{|c|}{ Age group(yrs) } & & \\
\hline & Boys(\%) & Girls(\%) & & \\
\hline $4-6$ & $6(13.33)$ & $5(19.23)$ & II(I5.49) & \\
\hline $7-9$ & $8(17.77)$ & $3(11.53)$ & II(I5.49) & \\
\hline $10-12$ & $20(44.44)$ & I4(53.84) & $34(47.88)$ & 0.213 \\
\hline $13-15$ & II (24.44) & $4(15.38)$ & $15(21.12)$ & \\
\hline Total & $45(63.38)$ & $26(36.6 I)$ & 7I & \\
\hline
\end{tabular}

Prevalence of stunting in respondents with relation to age group

Altogether 39 respondents were stunted, among them 27(69.23\%) were boys and $12(30.76 \%)$ were girls. The highest number of respondents were stunted in 10-12years age of 19(48.71\%) followed by $13-15 y$ ears age with $12(30.76 \%)$. The association of stunting in relation to gender and age group was statistically insignificant $(\mathrm{p}=0.367)$. The results are shown in Table 5 .

Table 5 Association of stunting in relation to gender and age group

\begin{tabular}{|c|c|c|c|c|}
\hline \multirow{3}{*}{ Age group(yrs) } & \multicolumn{2}{|l|}{ Gender } & \multirow{3}{*}{-Total(\%) } & \multirow{3}{*}{ p-value } \\
\hline & & & & \\
\hline & Boys(\%) & Girls(\%) & & \\
\hline $4-6$ & $4(|4.8|)$ & I(8.33) & $5(12.82)$ & \\
\hline $7-9$ & $3(I I . I I)$ & 0 & $3(7.69)$ & \\
\hline $10-12$ & $13(48.14)$ & $6(50)$ & $19(48.71)$ & 0.367 \\
\hline $13-15$ & $7(25.92)$ & $5(4 \mid .66)$ & $12(30.76)$ & \\
\hline Total & $27(69.23)$ & $12(30.76)$ & 39 & \\
\hline
\end{tabular}




\section{Discussion}

Globally, nutritional status is considered as the best indicator of the well-being of young children. ${ }^{10}$ More than $90 \%$ of the global burden of malnutrition is attributable to 36 countries of the world. ${ }^{13}$ The problem of malnutrition in developing countries are at alarming magnitude with a growing concern over the child health with rapid economic growth and social changes all over the world. Major determinant of health status in an adult is their nutritional status in childhood. Several studies have shown that dietary and environmental constraints are the major determinants of differences in growth performance between school children of developing and developed countries. ${ }^{14}$ Because school age is considered as a dynamic period of growth and development where children undergo physical, mental, emotional and social changes ${ }^{4,10,14}$ Underweight is defined as low weight-for-age and it reflects past(chronic) and present(acute) under nutrition. Stunting is defined as a low height-for-age for children, and it measures the past(chronic) child under nutrition. Wasting is defined as low weight-for-height for children, and it is a measure of current or acute under nutrition. Body mass index(BMI) is a simple index of weight-for-height that is commonly used to classify underweight, overweight and obesity. It is defined as the weight in kilograms divided by the square of the height in meters $\left.\left(\mathrm{kg} / \mathrm{m}^{2}\right)\right)^{7,10}$ This study revealed that total of 135 students examined for weight for age, height for age and Body mass index for age where 82(60.74\%) were boys and $53(39.25 \%)$ were girls. The prevalence of underweight, thinness and stunting among school children were $7.40 \%, 52.59 \%$ and $28.88 \%$ respectively. A similar type of study was conducted by Mansur et al., ${ }^{12}$ reported the prevalence of underweight, thinness and stunting was $30.85 \%, 10.05 \%$ and $24.54 \%$ respectively. ${ }^{12}$ Bose et al. ${ }^{15}$ found $16.9 \%$ were underweight, $17.2 \%$ were stunting and $23.1 \%$ were thinness among children. ${ }^{15}$ Similarly, the study done by Shivaprakash and Joseph 2014 reported the overall prevalence of underweight and stunting in the studied school children was $30.3 \%$ and $27.9 \%$ respectively. ${ }^{16}$ Singh 2014 reported the prevalence of underweight was $28.9 \%$, stunted height was $21.8 \%$ among children. ${ }^{17}$ Joshi et al., ${ }^{18}$ highlights that the prevalence of underweight was $26 \%$ amongst children from Kaski district of Western Nepal in 2011. ${ }^{18}$ Anjum et al., ${ }^{19}$ also reported the prevalence of underweight was $11.1 \%$ among children from Kashmir, India. ${ }^{19}$ These above results are not in accord with this study. This may be due to the problem of poor nutrition and middle class family with limited income. The urban middle class always tries to compromise on nutritious diet in order to save money to purchase luxurious items. Most of the mothers save money to buy expensive household items by curtailing expenses on food and feeding children rice, pickle or curd rice and buttermilk daily. But such diet ultimately leads to health problems even if the children may be eating adequate quantity of rice with lethargy, poor IQ and mental alertness. It signifies acute nutritional problem probably due to illness like diarrheal morbidity and/or food shortage. High chronic under nutrition also signifies children's failure to grow having its impact on both physical and mental capacity of the affected children. The present study signifies that most of the boys $(70 \%)$ were found to be underweight than girls(30\%). A similar trend has been reported by Ghosh et al., ${ }^{20}$ who observed that the prevalence of underweight was higher among boys(63.1\%) than girls(46.09\%) in Kathmandu valley in $2009 .{ }^{20}$ In another study, Ogechi et al., ${ }^{21}$ also reported the higher prevalence of underweight among boys $(63.1 \%)$ than girls(53.6\%) in Abia state, Nigeria. ${ }^{21}$ Similar type of findings was also obtained in the study designed by Shivaprakash et al., ${ }^{16}$
The above all study shows the prevalence of underweight in boys were more than girls which is in accordance with this study. This may be due poor diet taken by boys with lack of vitamins and minerals. Other reason may be that the boys are more influenced by environmental stress than the girls. Boys are more likely to display impact of chronic under nutrition, especially in environments with repeated infections and exposure to toxins and air pollutants. The highest number of prevalence of underweight among boys were in the age of 7-9years with $71.42 \%$ and among girls were equally in 4-6, 10-12 and 13-15years. The relation to gender and age group of underweight in children was found statistically insignificant $(\mathrm{p}=0.451)$. But in the study conducted by Shiva Prakash and Joseph 16 2014 among the boys underweight was seen more commonly in the age group 6-7years (44.4\%) and among girls in 11-12year age group $(34.1 \%) .{ }^{16}$ which is not in accord with the present study. The present study found $63.38 \%$ boys and $36.61 \%$ girls were thin according to age. The prevalence of wasting was found higher in boys than the girls in $10-12$ years with $47.88 \%$. The second most age where wasting among children was in $13-15$ years with $21.12 \%$. The association of thinness in relation to gender and age group was found to be statistically insignificant $(\mathrm{p}=0.213)$. Rao et al. ${ }^{22}$ utilizing the National Nutrition Monitoring Bureau data reported a similar trend regarding the prevalence of wasting among tribal male $(63.0 \%)$ and female $(42.0 \%)$ from nine Indian states. ${ }^{22}$ Venkaiah et al. ${ }^{23}$ also reported that the prevalence of thinness was higher in male $(53.1 \%)$ than in female $(39.5 \%){ }^{23}$ which is in concurrence with this study. The present study showed the higher prevalence of thinness in 10-12 and 13-15years ages. This may be the disturbance in dietary pattern, food behaviour, lack of balance diet and overload of the study and several types of unhygienic foods contributes to under nutrition among children. This study highlights that the higher prevalence of stunting in boys was $69.23 \%$ while in girls was $30.76 \%$. Among both boys and girls, stunting was noted more commonly in both boys and girls in the age group $10-12$ years with $48.14 \%$ boys and $50 \%$ girls. The relation of stunting to gender and age group was found to be statistically insignificant $(\mathrm{p}=0.367)$. In a study, Medhi et al. ${ }^{24}$ reported that $50.1 \%$ of boys and $43.1 \%$ of girls from Assam, India suffered from stunting. ${ }^{24}$ Ogechi et al., ${ }^{21}$ also reported that the prevalence of stunting was higher among male(67.3\%) than female children(57.8\%) in Abia state, Nigeria. ${ }^{21}$ Similar findings were also obtained in the study conducted by Shivaprakash and Joseph ${ }^{16}$ which is in settlement of this study. ${ }^{16}$ This may be due to families with more children particularly, poor families experience more economic strain for food consumption and generally devote less time to take care of their children hence they are more likely to suffer from poor nutritional status. Parasites can affect the nutrition and growth of children by depriving them of nutrients, impairing intestinal absorption of fat, nitrogen and vitamin A, and reducing food intake may perhaps be the other reasons. As stunting reflects past nutrition, the finding indicates that these children may have had experiences with poor diets and infections during their early childhood and perhaps were continuously living with similar conditions as a consequence of poverty and modification of food habits with low biological value.

\section{Conclusion}

The present study concludes that there was an emerging problem of under nutrition among school children when assessed using WHO cut-offs. The prevalence of under nutrition in terms of weight for age was low, height for age was moderate and BMI for age was high. 
There is a significant gender difference in anthropometric indices in boys and girls in the study population. Most of the children in this study had a poor nutritional status. School health screening program should be an essential part of school health services for descending trend of the prevalence of under nutrition among children. Mothers of these children should be educated about the importance of balanced diet. Consumption of foods like cereals, pulses, green leafy vegetables, roots and tubers, sugar and jiggery, fats and oil, milk and milk products, fruits etc., should be promoted. Interventions such as skills-based nutrition education, fortification of food items, effective infection control, and training of public healthcare workers and delivery of integrated programs are recommended. Government should introduce awareness programs through community participation, involvement of NGOs and other sectors affording nutritious foods.

\section{Acknowledgments}

Authors wish to acknowledge their sincere thanks to nursing instructors Ms. Biprasa Yadav, Ms. Priyanka Sah and $1^{\text {st }}$ year B.Sc nursing students $\left(4^{\text {th }}\right.$ Batch) of Krishna Medical Technical Research Centre (KMTRC), Janakpur, Nepal for their mutual co-operation and consistent support during this study

\section{Conflict of interest}

Author declares that there is no conflict of interest.

\section{References}

1. Khor GL. Food-based approaches to combat the double burden among the poor: challenges in the Asian context. Asia Pac J Clin Nutr. 2008;17(Suppl 1):111-115.

2. Bhargava M, Aggarwal P, Kandpal DS, et al. Magnitude of undernutrition in urban and rural school-going children of district dehradun using who reference standards. Natl J Community Med. 2015;6(4):452-457.

3. Dawani N, Afaqand A, Bilal S. Oral health knowledge, attitude and practices amongst teachers of public school set-up of Karachi, Pakistan. J Dow Univ Health Sci Karachi. 2013;7(1):15-19.

4. Yadav K, Prakash S. Knowledge, Attitude and Practice on Dental Caries and Oral Hygiene among Medical Students at Janaki Medical College Teaching Hospital. Int J Med Biomed Sci. 2016;1(2):22-31.

5. St Leger L, Young IM. Creating the document : Promoting health in schools: from evidence to action. Glob Health Promot. 2009;16(4):69-71.

6. Rezaeian S, Ahmadzadeh J, Esmailnasab N, et al. Assessment of Health and Nutritional Status in Children Based on School Screening Programs Health Scope. Health Scope. 2014;3(1):1-5.

7. Fazili A, Abid AM, Iqbal MP, et al. Nutritional Status of School Age Children (5-14years) in a Rural Health Block of North India (Kashmir) Using WHO Z-Score System. Online Journal of Health and Allied Sci. 2012;11(2):1-3.
8. Nowsin I, Begum N, Akber BE, et al. Study on nutritional status of rural school children of Bangladesh. Bangladesh J Physiol Pharmacol. 2014;30(1):6-10.

9. Waterlow IC, Buzina R, Keller W, et al. The presentation and use of height and weight data for comparing the nutritional status of groups of children under the age of 10years. Bull World Health Organ. 1977;55(4):489-498.

10. Muller O, Krawinkel M. Malnutrition and health in developing countries. CMAJ. 2005;173(3):279-286.

11. Kathmandu: Ministry of Health and Population Nepal. Nepal Demographic and Health Survey Preliminary Report. India; 2011.

12. Mansur DI, Haque MK, Sharma K, et al. A Study on Nutritional Status of Rural School going Children in Kavre District. Kathmandu Univ Med J. 2015;50(2):146-151.

13. http://www.undp.org.bd/projects/proj_detail.php?pid=57

14. Quinn VJ, Chiligo Mpoma MO, et al. The growth of Malawian preschool children from different socioeconomic groups. Eur $J$ Clin Nutr. 1995;49(1):66-72.

15. Bose K, Bisai S, Mukherjee S. Anthropometric characteristics and nutritional status of rural school children. The Internet J Biological Anthropol. 2007;2(1):1-6.

16. Shivaprakash NC, Joseph RB. Nutritional Status of Rural SchoolGoing Children (612Years) of Mandya District, Karnataka. Int J Scientific Study. 2014;2(2):39-43.

17. Singh PS. Malnutrition among primary school children in Hyderabad, Andhra pradesh, India. Int J Tech Res Applicat. 2014;2(1):36-39.

18. Joshi HS, Gupta R, Joshi MC, et al. Determinants of Nutritional Status of School Children - A Cross Sectional Study in the Western Region of Nepal. National J Integrated Res Med. 2011;2(1):10-15.

19. Anjum F, Abid AM, Iqbal MP, et al. Nutritional Status of School Age Children (5-14 years) in a Rural Health Block of North India (Kashmir) Using WHO Z-Score System. Online J Health and Allied Sci. 2012;11(2):1-3.

20. Ghosh A, Adhikari P, Chowdhury SD, et al. Prevalence of undernutrition in Nepalese children. Ann Hum Biol. 2009;36(1):38-45.

21. Ogechi UP, Onimawo Ignatius AU, Andrew U. Nutritional Status and Energy Intake of Adolescents in Umuahia Urban, Nigeria. Pakistan J Nutri. 2007;6(6):641-646.

22. Rao KM, Laxmaiah A, Venkaiah K, et al. Diet and nutritional status of adolescent tribal population in nine states of India. Asia Pac J Clin Nutr. 2006;15(1):64-71

23. Venkaiah K, Damayanti K, Nayak MU, et al. Diet nutritional status of rural adolescents in India. Eur J Clin Nutri. 2002;56(11):1119-1125.

24. Medhi GK, Hazarika NC, Mahanta J. Nutritional status of adolescents among tea garden workers. Indian J Pediatr. 2007;74(4):343-347. 